\title{
Bimodal age distribution at diagnosis in breast cancer persists across molecular and genomic classifications
}

\author{
Emma H. Allott ${ }^{1,9}$ (1) - Yue Shan ${ }^{2}$ - Mengjie Chen ${ }^{3}$. Xuezheng Sun ${ }^{4}$. Susana Garcia-Recio ${ }^{5}$. Erin L. Kirk ${ }^{4}$. \\ Andrew F. Olshan ${ }^{4,5}$. Joseph Geradts ${ }^{6} \cdot$ H. Shelton Earp ${ }^{5,7} \cdot$ Lisa A. Carey ${ }^{5,7}$. Charles M. Perou ${ }^{5}$. Ruth M. Pfeiffer ${ }^{8}$. \\ William F. Anderson ${ }^{8} \cdot$ Melissa A. Troester ${ }^{4,5,10}$
}

Received: 9 July 2019 / Accepted: 10 September 2019 / Published online: 18 September 2019

(c) The Author(s) 2019

\begin{abstract}
Purpose Female breast cancer demonstrates bimodal age frequency distribution patterns at diagnosis, interpretable as two main etiologic subtypes or groupings of tumors with shared risk factors. While RNA-based methods including PAM50 have identified well-established clinical subtypes, age distribution patterns at diagnosis as a proxy for etiologic subtype are not established for molecular and genomic tumor classifications.

Methods We evaluated smoothed age frequency distributions at diagnosis for Carolina Breast Cancer Study cases within immunohistochemistry-based and RNA-based expression categories. Akaike information criterion (AIC) values compared the fit of single density versus two-component mixture models. Two-component mixture models estimated the proportion of early-onset and late-onset categories by immunohistochemistry-based ER $(n=2860)$, and by RNA-based ESRI and PAM50 subtype $(n=1965)$. PAM50 findings were validated using pooled publicly available data $(n=8103)$.

Results Breast cancers were best characterized by bimodal age distribution at diagnosis with incidence peaks near 45 and 65 years, regardless of molecular characteristics. However, proportional composition of early-onset and late-onset age distributions varied by molecular and genomic characteristics. Higher ER-protein and ESRI-RNA categories showed a greater proportion of late age-at-onset. Similarly, PAM50 subtypes showed a shifting age-at-onset distribution, with most pronounced early-onset and late-onset peaks found in Basal-like and Luminal A, respectively.

Conclusions Bimodal age distribution at diagnosis was detected in the Carolina Breast Cancer Study, similar to national cancer registry data. Our data support two fundamental age-defined etiologic breast cancer subtypes that persist across molecular and genomic characteristics. Better criteria to distinguish etiologic subtypes could improve understanding of breast cancer etiology and contribute to prevention efforts.
\end{abstract}

Keywords Bimodality $\cdot$ Estrogen receptor $\cdot$ Etiology $\cdot$ Mixture model $\cdot$ Race $\cdot$ Subtype $\cdot$ PAM50

\section{Introduction}

Breast cancer heterogeneity may obscure etiologic risk factor associations if tumor subtypes are inadequately or incorrectly classified [1]. Etiologic studies generally group breast

Electronic supplementary material The online version of this article (https://doi.org/10.1007/s10549-019-05442-2) contains supplementary material, which is available to authorized users.

Emma H. Allott

e.allott@qub.ac.uk

Melissa A. Troester troester@unc.edu

Extended author information available on the last page of the article cancer into two or more protein-based subtypes using immunohistochemistry expression of estrogen receptor (ER), progesterone receptor (PR), and HER2 [2]. On the other hand, efforts to classify breast cancer into four genomic-intrinsic subtypes have focused on determining targeted therapies and cancer-specific clinical outcomes [3]. However, for cancer prevention efforts, optimizing subtype classification for etiologic subtypes is the key for understanding risk factor associations.

There is emerging evidence, based on bimodal age frequency distributions at diagnosis, that breast cancer can be divided into just two etiologically distinct subtypes [4]. Breast cancer bimodality has been observed across categories of ER status, tumor characteristics and histologic 
subtypes [5]. Bimodality has also been observed in different populations, for example, in both black and white breast cancer cases in the US [6] and South Africa [7]. However, prior evidence for breast cancer bimodality has been based on national cancer registries, which lack detailed molecular and genomic data. No studies, to our knowledge, have comprehensively explored evidence for bimodal age distribution at diagnosis across quantitative protein-based (i.e., percent ER-positivity) or RNA-based (i.e., ESRI and PAM50) tumor characteristics.

Using data from the Carolina Breast Cancer Study, we visualized age distributions at diagnosis and applied twocomponent mixture models across categories of breast cancer cases defined by molecular and genomic characteristics. We also sought to identify molecular or genomic features that could separate etiologically distinct breast cancers into single or unimodal age distributions at diagnosis.

\section{Methods}

\section{Study design and participants}

The Carolina Breast Cancer Study is a case-control study conducted in North Carolina (NC) in three phases (Phase 1: 1993-1996, Phase 2: 1996-2001 and Phase 3: 2008-2013), the details of which have been described previously [8]. Briefly, invasive breast cancer cases in women between 20 and 74 years of age were identified using rapid case ascertainment in cooperation with the NC Central Cancer Registry, and African American and young cases (aged 20-49 years) were oversampled [8]. The study was approved by the Office of Human Research Ethics at the University of North Carolina at Chapel Hill (UNC) and written informed consent was obtained from each participant. We used data from all invasive breast cancer cases across all three Carolina Breast Cancer Study phases $(n=4806)$ for the present analysis (Supplementary Table 1). Tumor size and lymph node status were abstracted from medical records, and these data were available for $n=4618(96 \%)$ and $n=4751(99 \%)$ study participants, respectively. Combined grade was centrally assigned by a single breast cancer pathologist (JG) using the Nottingham breast cancer grading system [9], and was available for $n=3408(71 \%)$ cases.

\section{Immunohistochemistry analyses}

All quantitative ER protein data, available for a total of $n=2860(60 \%)$ cases (Supplementary Table 1), were obtained from immunohistochemistry staining. Immunohistochemistry expression of ER was abstracted from the medical records for $n=496$ cases from Phases 1 and 2 . For the remainder $(n=206$ cases from Phases 1 and 2, and $n=2158$ cases from Phase 3), formalin-fixed paraffinembedded tumor blocks were requested from participating pathology laboratories. Tumor blocks were used to generate whole sections for all cases in Phases 1 and 2, and for 473 $(22 \%)$ cases in Phase 3. For the remainder of cases in Phase $3(n=1685,78 \%)$, tumor blocks were used to generate tissue microarrays, as previously described [2]. Immunohistochemistry staining was performed at the Immunohistochemistry Core Laboratory at UNC, and quantified using automated image analysis, as previously described [2]. When data were combined across Phases, demographic and tumor characteristics of cases with and without quantitative ER were similar (Supplementary Table 1).

Among ER-positive cases, we categorized ER expression as borderline $(\geq 1-<10 \%)$, low $(\geq 10-<40 \%)$, intermediate $(\geq 40-<80 \%)$, high $(\geq 80 \%)$, and very high $(\geq 95 \%)$. Expression categories were selected to be in line with a previous study [10] and to avoid sparse sample sizes in any given category.

\section{Genomic analyses}

Nanostring assays were used to measure PAM50 gene signature [11], which includes ESR1 gene, on $n=1965$ cases from the Carolina Breast Cancer Study. Assays were performed in the Rapid Adoption Molecular (RAM) laboratory at UNC as previously described [12, 13]. Cases with and without RNA data had similar demographic and tumor characteristics (Supplementary Table 1). PAM50 subtype was determined using a similarity-to-centroid approach as previously described $[11,13]$ to classify breast tumors into four intrinsic subtypes (Luminal A, Luminal B, HER2-enriched, Basal-like). Tumors classified as normal-like $(n=66)$ were excluded from our analysis, given that this classification is thought to arise from extensive normal epithelial or stromal content in the tumor [14]. ESRI gene expression was median-centered and standardized to zero mean and unit variance, then categorized into quartiles based on expression levels in all cases.

We assembled a large validation genomics dataset of invasive breast cancer cases $(n=8103)$ by pooling publicly available data from The Cancer Genome Atlas (TCGA) [15], the Molecular Taxonomy of Breast Cancer International Consortium (METABRIC; EGAS00000000083) [16, 17], the Sweden Cancerome Analysis Network-Breast Initiative (SCAN-B; GSE81538 and GSE96058) [18], the UNC337 dataset from the UNC Microarray Database (GSE18229) [19], a previously pooled set of human breast tumors (GSE26338, GSE2034, GSE12276, GSE2603) [20] and the MD Anderson Cancer Center dataset (MDACC; GSE25066) [21]. PAM50 subtype was assigned in the validation cohort as described above for the Carolina Breast Cancer Study. 


\section{Statistical analysis}

We constructed smoothed age frequency distributions at diagnosis (i.e., density plots) across categories of ER protein expression, across quartiles of ESRl gene expression, and according to the intrinsic PAM50 subtype. Within each category defined by molecular or genomic characteristics, we assessed the performance of a single density model versus a two-component mixture model. We explored two different parameterizations of the data: a normal density, and a semi-nonparametric density with a polynomial component to allow for skewness and heavy tails in the distributions. Single density and two-component mixture models were each evaluated using normal density and semi-nonparametric density parameters, producing a total of four models for comparison within each molecular or genomic category. Models were compared using Akaike information criterion (AIC) values, with smaller AIC values indicating a better fit. Using this approach, we first identified the top-ranking single density model and the top-ranking two-component mixture model, and we then compared the goodness of fit between these two models using the difference in their AIC values $\left(\Delta_{\mathrm{AIC}}\right)$, with $\Delta_{\mathrm{AIC}}>10$ indicating a substantial difference in the goodness of fit between the two models and a $\Delta_{\text {AIC }} 4-10$ indicating a difference in the goodness of fit between the models, albeit with slightly less confidence than a value $>10$ [22]. For all categories determined to be bimodal, two-component statistical mixture models were applied to estimate the mixing proportion of early-onset (p-early) and late-onset (p-late) modes or peaks within each category, as previously described [5, 23].

Analysis was performed in the validation cohort as described above for the Carolina Breast Cancer Study.

Statistical analysis was conducted in SAS version 9.4 (SAS Institute, Cary, NC).

\section{Results}

\section{Age distributions at diagnosis by ER and ESR1 expression level}

As illustrated in Fig. 1, the age distribution at breast cancer diagnosis showed a bimodal pattern in every ER category with early- and late-onset incidence peaks (or modes) near ages 45 and 65 years, respectively. While the proportion of cases within the late-onset peak decreased across decreasing categories of ER expression (Fig. 1, green line), the modal ages remained unchanged near 45 and 65 years. ER-negative cases $(<1 \% \mathrm{ER})$ and those with borderline $(\geq 1-<10 \%)$, low $(\geq 10-<40 \%)$, and intermediate $(\geq 40-<80 \%)$ ER expression levels had predominant early-onset peaks. In contrast, cases with high ( $\geq 80 \%$ and $\geq 95 \%$ ) ER expression had predominant late-onset peaks (blue line). A bimodal pattern with shifting age-at-onset distributions but stable modes near 45 and 65 years was also observed when different clinical definitions of ER-positive status (i.e., $\geq 1 \%$ vs. $\geq 10 \%$ ) were considered (Supplementary Fig. 1 and Supplementary Table 2).

Consistent with bimodal age distributions at diagnosis for all density plots (Fig. 1), a two-component mixture model fit the data better than a single density for all categories of ER expression (Table 1). As shown in Table 1, the majority of $\Delta_{\mathrm{AIC}}$ values were greater than 10 , indicating substantial confidence that the two-component mixture model provided the best fit for our data. One exception was noted for the ER-borderline group, where $\Delta_{\text {AIC }}$ lay between 4 and 10 , still indicating that the two-component mixture model provided better fit, albeit with a slightly lower certainty. Cases with lower ER levels had a greater probability of belonging to the early-onset than the late-onset age distribution (e.g., p-early $=0.77,0.88,0.75$, and 0.74 for cases with negative, borderline, low and intermediate ER expression, respectively). The proportion of early-onset age distribution further declined for cases with high and very high ER expression (e.g., $p$-early $=0.58$ and $p$-early $=0.50$, for cases with $\geq 80 \%$ and $\geq 95 \%$ ER expression levels, respectively). While ER expression level affected the mixing proportion, the early- and late-onset modes remained unchanged near ages 45 and 65 .

Similar patterns were observed in race-stratified analyses (Supplementary Figs. 2, 3 and Supplementary Table 2), albeit with more pronounced early-onset peaks in black vs. white women both overall (e.g., $p$-early $=0.66$ for white women, $p$-early $=0.75$ for black women) and by ER status (e.g., $p$-early $=0.61$ and 0.79 for cases with $\mathrm{ER} \geq 10 \%$ and $<10 \%$ in white women, $p$-early $=0.72$ and 0.83 for cases with $\mathrm{ER} \geq 10 \%$ and $<10 \%$ in black women).

As shown in Fig. 2, classifying cases by quartiles of ESRI gene expression recapitulated bimodal age distributions at diagnosis observed across categories of immunohistochemistry-based ER expression levels. While modal ages remained constant near ages 45 and 65, the proportion of late-onset cases gradually decreased across decreasing quartiles of ESR1 expression (Q4 p-late $=0.31, \mathrm{Q} 3 p$-late $=0.25$, $\mathrm{Q} 2$-late $=0.22$, Q1 $p$-late $=0.13$; as shown in Table 1 ).

\section{Age distributions at diagnosis by genomic and tumor characteristics}

In Fig. 3, we show that age at diagnosis was bimodally distributed for all PAM50 intrinsic subtypes. Basal-like, HER2-enriched, and Luminal B cancers all had predominant early-onset peaks with minor late-onset peaks, whereas the late-onset peak was most pronounced in Luminal A cancers. 

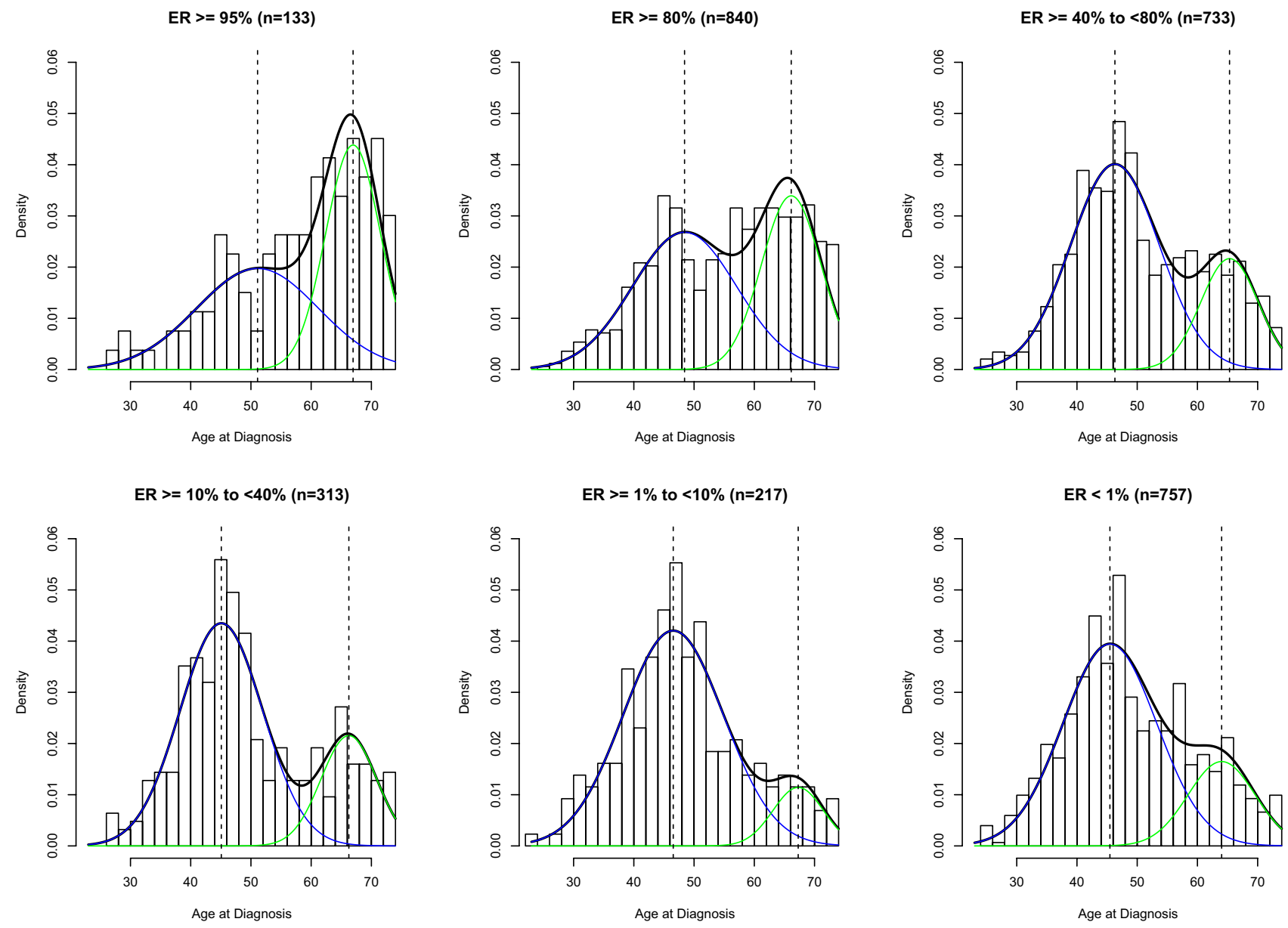

Fig. 1 Density plots showing age frequency at diagnosis for invasive breast cancer cases from the Carolina Breast Cancer Study across immunohistochemistry-based ER categories

In keeping with the bimodal appearance of the density plots, we found that each intrinsic subtype was best described by a two-component mixture model (Table 1). The proportion of late-onset age distribution decreased across intrinsic subtype categories, from Luminal A $(p$-late $=0.30)$, Luminal B ( $p$-late $=0.26)$, HER2-enriched $(p$-late $=0.16)$, with Basal-like showing the lowest probability of late-onset disease ( $p$-late $=0.11$; Table 1$)$. As we observed for ER and ESRI expression, while the mixing proportion was affected by intrinsic tumor subtype, the early- and late-onset modal ages remained near ages 45 and 65. As shown in Table 1, the majority of $\Delta_{\text {AIC }}$ values were greater than 10 , indicating substantial confidence that the two-component mixture model provided the best fit for our data. One exception was noted for the HER2-enriched subtype, where $\Delta_{\text {AIC }}$ was equal to 10 , still indicating that the two-component mixture model provided better fit, albeit with a slightly lower certainty. Similar patterns were observed in a large validation dataset of $>8000$ invasive breast cancers, where all PAM50 subtypes were bimodally distributed with a declining probability of late-onset from Luminal A to Luminal B to HER2-enriched to Basal-like, mirrored by an increasing probability of early-onset across these subtypes (Supplementary Fig. 4 and Supplementary Table 3).

Likewise, all tumors categorized by high-risk and lowrisk tumor characteristics were best described by a twocomponent mixture model, with modal ages near 45 and 65 years (Supplementary Fig. 5). The proportion of earlyonset cancers increased with increasing combined grade. Similarly, larger tumors and tumors with multiple positive lymph nodes were more likely to belong to the earlyonset distribution, compared to smaller and node-negative tumors (Supplementary Table 4).

Combined categories of molecular, genomic and tumor characteristics also failed to isolate a single population, with every combination best described by a two-component mixture model (data not shown). 
Table 1 Comparison of single density versus two-component mixture model fit across molecular tumor categories in Carolina Breast Cancer Study cases, and estimates for early-onset and late-onset modes and mixing proportions for the selected model

\begin{tabular}{|c|c|c|c|c|c|c|c|c|c|}
\hline & \multirow{2}{*}{$\begin{array}{l}\text { Total cases, } \\
\mathrm{n}(\%)\end{array}$} & \multirow{2}{*}{$\begin{array}{l}\text { Median } \\
\text { age at } \\
\text { diagnosis } \\
\text { (years) }\end{array}$} & \multicolumn{3}{|c|}{ Model fit (AIC) } & \multicolumn{2}{|c|}{ Mode $^{\mathrm{b}}$ (years) } & \multicolumn{2}{|c|}{ Mixing proportion ${ }^{\mathrm{b}}$} \\
\hline & & & $\begin{array}{l}\text { AIC- } \\
\text { single density }\end{array}$ & $\mathrm{AIC}_{\text {two-component mixture }}$ & $\begin{array}{l}\Delta_{\text {AIC }}^{\mathrm{a}} \\
\left(\mathrm{AIC}_{\text {single }}-\right. \\
\left.\mathrm{AIC}_{\text {mixture }}\right)\end{array}$ & Early onset & Late onset & Early onset & Late onset \\
\hline \multicolumn{10}{|l|}{$\begin{array}{l}\text { Protein-based } \\
\text { categories }\end{array}$} \\
\hline Overall & 2860 & 50 & $21,947.02$ & $21,657.60$ & 289.42 & 46 & 67 & 0.72 & 0.28 \\
\hline \multicolumn{10}{|l|}{$\begin{array}{l}\text { ER protein } \\
\text { expression }\end{array}$} \\
\hline$\geq 95 \%$ & $133(5)$ & 62 & 1022.84 & 998.24 & 24.60 & 51 & 67 & 0.50 & 0.50 \\
\hline$\geq 80 \%$ & $840(29)$ & 57 & 6455.88 & 6362.56 & 93.32 & 48 & 66 & 0.58 & 0.42 \\
\hline$\geq 40-<80 \%$ & $733(26)$ & 49 & 5560.16 & 5489.42 & 70.74 & 46 & 65 & 0.74 & 0.26 \\
\hline$\geq 10-<40 \%$ & $313(11)$ & 48 & 2396.44 & 2343.82 & 52.62 & 45 & 66 & 0.75 & 0.25 \\
\hline$\geq 1-<10 \%$ & $217(8)$ & 48 & 1637.76 & 1629.84 & 7.92 & 47 & 67 & 0.88 & 0.12 \\
\hline$<1 \%$ & $757(26)$ & 48 & 5728.58 & 5695.14 & 33.44 & 45 & 64 & 0.77 & 0.23 \\
\hline \multicolumn{10}{|l|}{$\begin{array}{r}\text { RNA-based } \\
\text { categories }\end{array}$} \\
\hline Overall & 1965 & 49 & $15,092.82$ & $14,899.46$ & 193.36 & 47 & 67 & 0.76 & 0.24 \\
\hline \multicolumn{10}{|l|}{$\begin{array}{l}\text { ESR1 gene } \\
\text { expression }\end{array}$} \\
\hline Quartile 4 & $492(25)$ & 53 & 3792.24 & 3722.54 & 69.70 & 48 & 67 & 0.69 & 0.31 \\
\hline Quartile 3 & $491(25)$ & 49 & 3738.00 & 3676.14 & 61.86 & 47 & 66 & 0.75 & 0.25 \\
\hline Quartile 2 & $491(25)$ & 49 & 3808.52 & 3770.84 & 37.68 & 47 & 67 & 0.78 & 0.22 \\
\hline Quartile 1 & $491(25)$ & 48 & 3730.72 & 3714.70 & 16.02 & 47 & 67 & 0.87 & 0.13 \\
\hline \multicolumn{10}{|l|}{$\begin{array}{l}\text { PAM50 sub- } \\
\text { type }\end{array}$} \\
\hline Luminal A & 898 (47) & 53 & 6886.04 & 6757.64 & 128.40 & 48 & 67 & 0.70 & 0.30 \\
\hline Luminal B & 269 (14) & 48 & 2071.28 & 2054.12 & 17.16 & 45 & 65 & 0.74 & 0.26 \\
\hline $\begin{array}{l}\text { Her2- } \\
\text { enriched }\end{array}$ & $174(9)$ & 48 & 1328.06 & 1318.02 & 10.04 & 47 & 67 & 0.84 & 0.16 \\
\hline Basal-like & $558(29)$ & 47 & 4260.84 & 4239.44 & 21.40 & 47 & 69 & 0.89 & 0.11 \\
\hline
\end{tabular}

${ }^{\text {a }}$ Positive values favor the two-component mixture model and negative values favor the single density model, with $\Delta_{\text {AIC }} 4-10$ indicating little support for the lower-ranking model and $\Delta_{\mathrm{AIC}}>10$ indicating essentially no support for the lower-ranking model [22]

${ }^{\mathrm{b}}$ Modes and mixing proportions are shown for the two-component mixture model, found to provide the best fit for all categories shown

\section{Discussion}

The identification of at least four distinct intrinsic breast cancer subtypes [24] has guided the development of targeted therapy and contributed to improved breast cancer survival rates. However, it has been posited that breast cancer is comprised of just two etiologically distinct groups $[4,25]$, with ER status currently serving as the most widely used surrogate of these two subtypes [26]. Though not optimized for this purpose, classifying tumors by ER status has advanced our understanding of breast cancer risk factors. For example, increasing parity is inversely associated with risk of ERpositive breast cancer but positively associated with risk of ER-negative breast cancer, an effect that can be partially offset by breastfeeding $[27,28]$. Under this proposed model, breast cancer is a two-component mixture of ER-positive and ER-negative tumor populations [4], with differences in quantitative levels of ER expression reflecting enrichment for one or other population. Building on this hypothesis, our work in the Carolina Breast Cancer Study shows that breast cancer bimodality is a robust characteristic observed across molecular and genomic tumor features.

Prior research using publicly available registry data from the US [5], as well as data from Europe [29], Africa [7, 30], and Asia [31], has established bimodal age at diagnosis as a universal feature of female breast cancer. Breast cancer bimodality has also been observed within categories defined by ER status [4], high-risk and low-risk tumor characteristics [32] and histologic subtype [5]. A notable exception to this bimodal age distribution at diagnosis is medullary carcinoma [5], a rare early-onset sporadic breast cancer that is linked to ER-negative and triple negative cancers, Basal-like 
ESR1 Q4 (n=492)

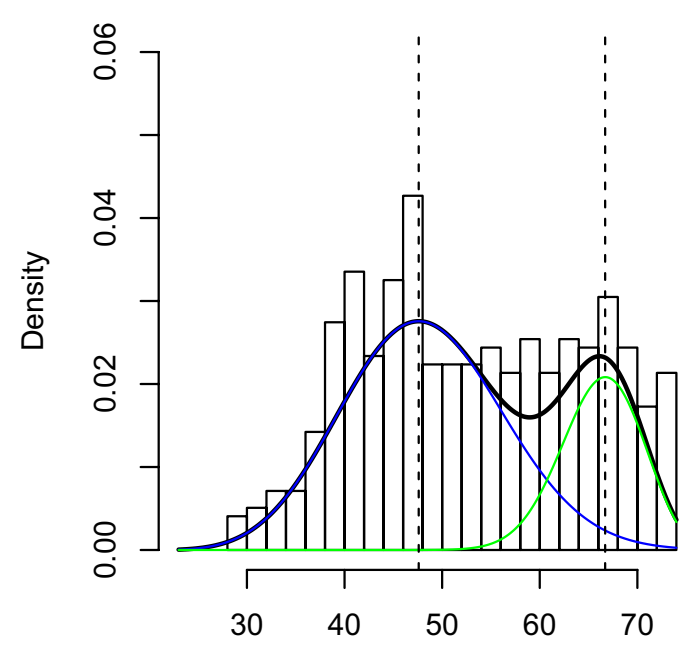

Age at Diagnosis

ESR1 Q2 ( $\mathrm{n}=491)$

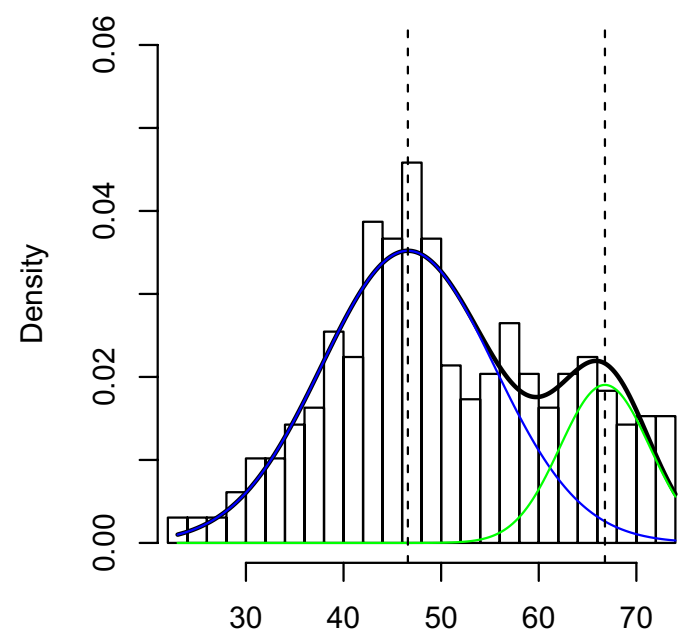

Age at Diagnosis
ESR1 Q3 $(\mathrm{n}=491)$

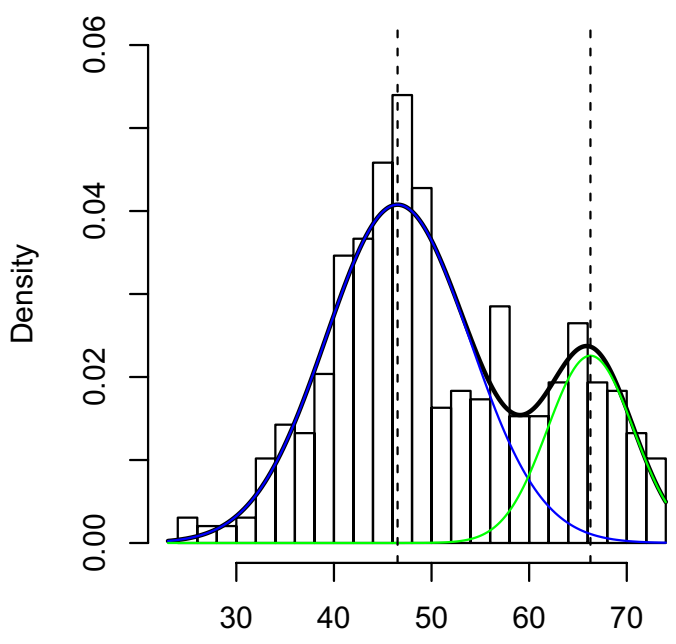

Age at Diagnosis

\section{ESR1 Q1 $(\mathrm{n}=491)$}

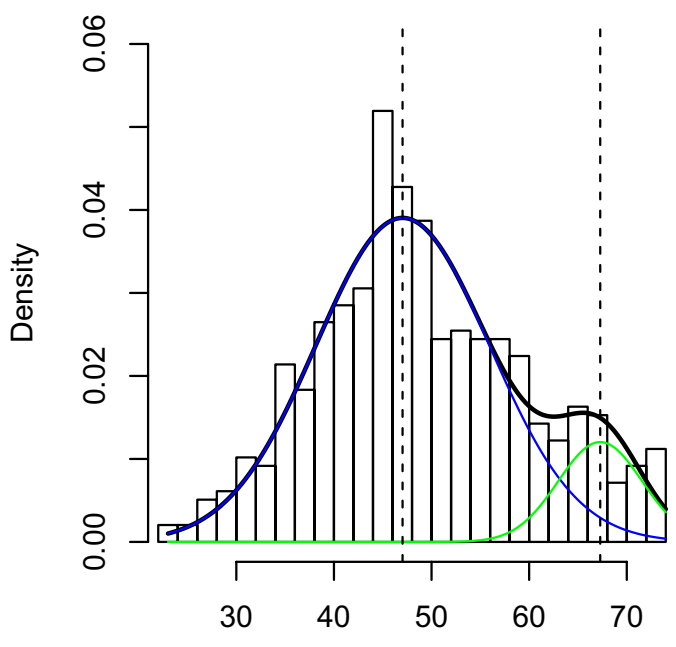

Age at Diagnosis

Fig. 2 Density plots showing age frequency at diagnosis for invasive breast cancer cases from the Carolina Breast Cancer Study across RNAbased ESR1 quartiles

tumor features [33], and the BRCAl mutation [34]. While developments in molecular and genomic tumor profiling technologies have advanced the field of breast cancer subtyping for prognosis and prediction, national cancer registries are limited to tumor characteristics reported in medical records and therefore lack these data. In the present study, we used quantitative ER expression and RNA data from the Carolina Breast Cancer Study to explore evidence for bimodality within groups defined by molecular and genomic features. We report that although certain molecular and genomic tumor characteristics enriched for either early-onset or late-onset breast cancer, we were unable to separate earlyonset from late-onset breast cancer using existing molecular or genomic classifications, or any combinations thereof.

Interpretation of quantitative immunohistochemistrybased ER levels has been subject to some controversy. Replacement of the radio ligand-binding assay with immunohistochemistry for measuring ER status was accompanied by observations that ER expression was bimodally distributed [35]. Rimm and others have argued that the bimodal 


\section{Luminal A $(n=898)$}

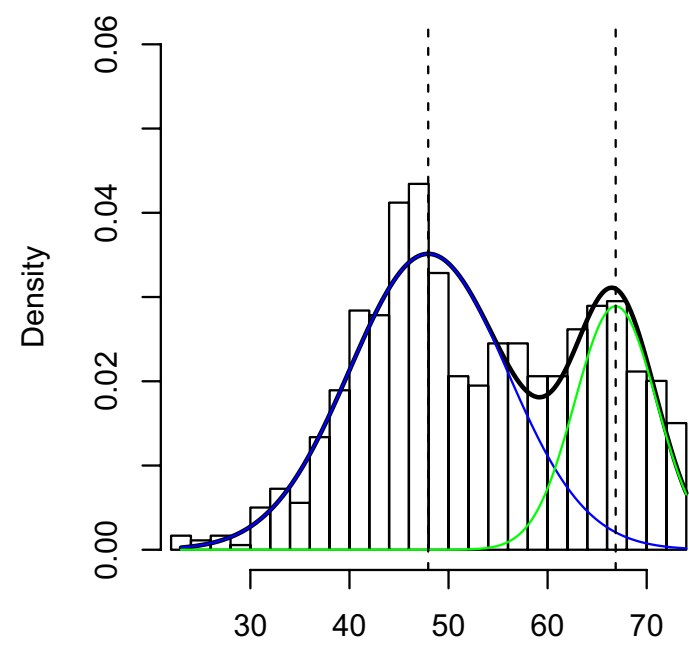

Age at Diagnosis

Her2-enriched $(n=174)$

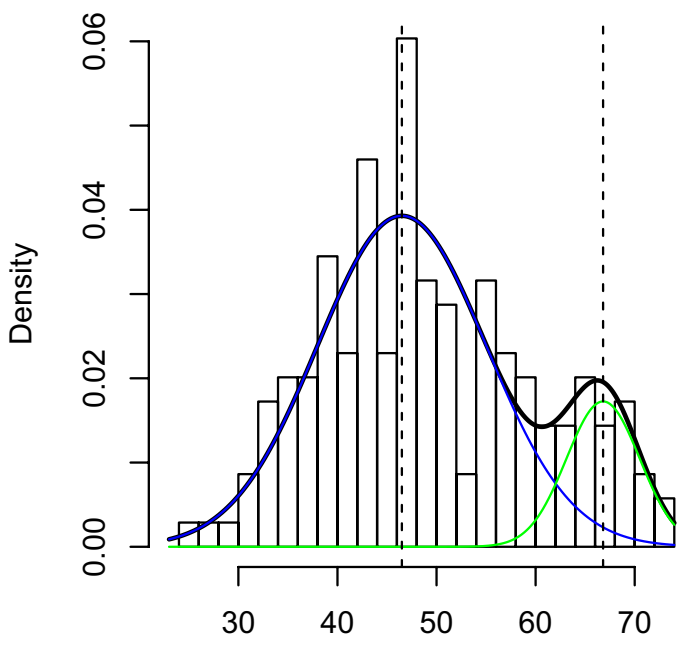

Age at Diagnosis

\section{Luminal $B(n=269)$}

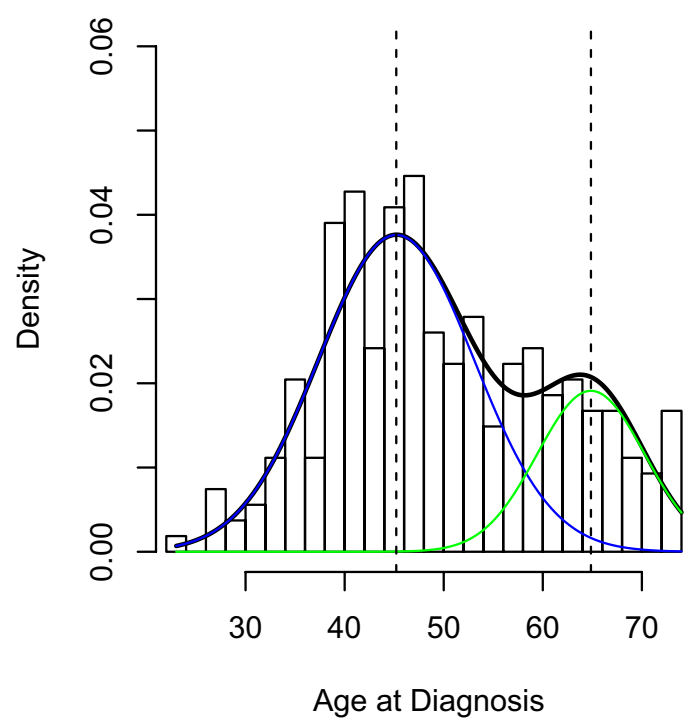

Basal-like $(n=558)$

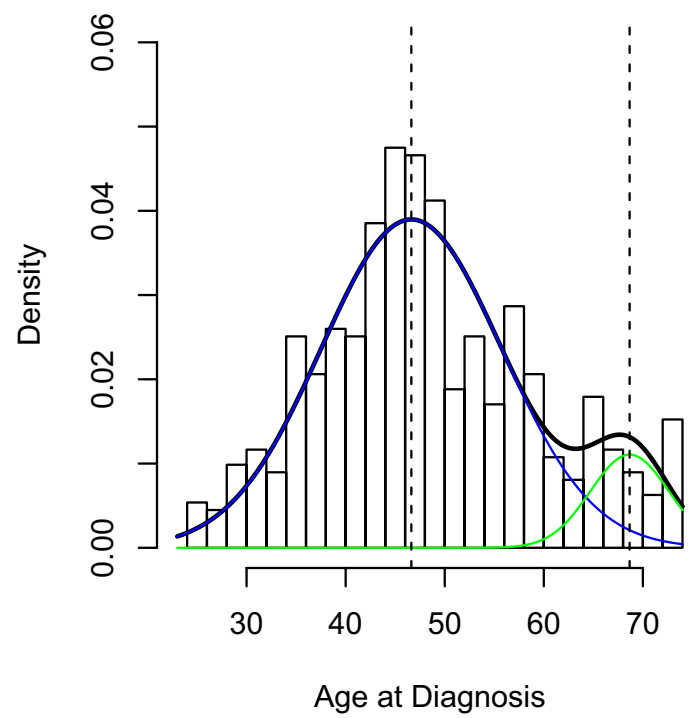

Fig. 3 Density plots showing age frequency at diagnosis for invasive breast cancer cases from the Carolina Breast Cancer Study across PAM50 intrinsic subtype

distribution of ER expression is an artifact of immunohistochemistry staining methods, which have been optimized to maximize the sensitivity of the assay $[36,37]$. Indeed, we have observed a greater dynamic range of ESRI expression, compared to that of immunohistochemistry-based ER expression which becomes saturated at higher levels of ESRI [38]. However, several studies have since shown evidence for bimodal distribution not only of quantitative immunohistochemistry-based ER expression [39] but also of ESRI levels $[39,40]$, which are not subject to concerns regarding immunohistochemistry methodology. Herein, we build on evidence for breast cancer bimodality by showing bimodal age-at-incidence across categories of immunohistochemistry-based ER expression, ESRI levels, as well as PAM50 intrinsic subtype. As such, this manuscript bolsters evidence for bimodal age distribution at diagnosis as a universal characteristic of female breast cancer.

Breast cancer bimodality is consistent with tumors being derived from two distinct progenitor cell types, basal/myoepithelial versus luminal [4]. Large-scale genomic analyses 
have recently challenged the classification of cancers according to their tissue-of-origin. Using multi-platform genomic analyses, Hoadley et al. found that although most tumor types were classified by tissue-of-origin, several distinct cancer types converged into common subtypes regardless of tissue-of-origin, while others diverged into multiple subtypes within the tissue-of-origin classifications [25]. Breast cancer provided one of the most striking examples of this divergence, with Luminal/HER2-enriched and Basal-like breast cancers forming separate clusters as distinct from each other as from other tissue-of-origin cancer types (e.g., lung). Moreover, this integrated analysis revealed that marked molecular differences were observed between epithelial tumors arising from basal cell versus secretory cell types, suggesting that cell type-of-origin dominates molecular taxonomy of breast and other cancer types [25]. Shared etiology across cancers with different tissue-of-origin but shared cell type-of-origin (e.g., smoking as a shared risk factor for squamous bladder, head and neck and non-small cell lung cancers) may highlight the importance of classifying breast cancer according to the cell type-of-origin for understanding breast cancer etiology. Future studies should pursue the identification of molecular characteristics that can separate etiologically distinct subtypes of breast cancer.

Our findings should be considered in the context of several limitations. First, though a population-based study, the Carolina Breast Cancer Study oversampled for young and African American women. Our analysis did not account for this sampling schema and thus our population distribution is shifted toward younger ages relative to national distributions of breast cancer incidence. This is highlighted by our finding that modal ages for early and late-onset distributions lie at ages 45 and 65, whereas data from SEER breast cancer cases show that modes are closer to 50 and 70 years of age [5]. Restricting SEER data to the age range of the Carolina Breast Cancer Study produced similar bimodal age distributions at diagnosis (data not shown), suggesting that the slightly younger modes in the Carolina Breast Cancer Study may be due to the restricted age range at breast cancer diagnosis in the Carolina Breast Cancer Study (20-74) versus SEER (currently 10-117). However, rather than the absolute modal age which depends on the age distribution in the underlying population, the key attribute of these modes is that they are stable across molecular categories. Second, lower numbers of cases particularly in ER-borderline (ER 1-10\%) and HER2-enriched categories may have limited our ability to discriminate between single density and twocomponent mixture models, as evidenced by $\Delta_{\text {AIC }}$ values between 4 and 10 . However, $\Delta_{\text {AIC }}$ values in this range still provide support for a bimodal age distribution at diagnosis for these subgroups, albeit with a slightly lower certainty than when $\Delta_{\text {AIC }}$ is greater than 10 [22]. Third, although we had insufficient sample size to perform race-stratified analysis for each of the molecular subtypes, we were able to perform race-stratified analyses both overall and by ER status. Indeed, our race-stratified results are in agreement with findings from SEER analyses [5, 6], showing a larger proportion of early-onset cases among black women. Strengths of this study include the large number of African American women, a racial group disproportionately affected by highrisk breast cancer [12], as well as access to high quality molecular and genomic data for a large number of breast cancer cases.

\section{Conclusions}

Using data from the Carolina Breast Cancer Study, we found evidence for a bimodal age distribution at breast cancer diagnosis both overall and within categories defined by molecular and genomic characteristics. While tumor subgroups defined by high-risk features (e.g., low immunohistochemistry-based ER levels, low ESRI expression, Basal-like subtype) showed enrichment for early-onset breast cancer, all of these categories and combinations thereof were best described by a two-component mixture model. Better criteria to distinguish these two etiologic subtypes could advance our understanding of breast cancer risk factors and inform prevention efforts.

Author contributions EHA, RMP, WFA and MAT conceived of the study. YS and RMP performed the analysis and EHA, MC, YS, RMP, and WFA interpreted the data. SGR collated the publicly available data, and helped to draft the manuscript. EK generated the PAM50 data. XS performed quality control and analysis of the PAM50 data. JG performed histological grading of the tumor tissue and helped to interpret the data. AFO, HSE, LAC, CMP, and MAT participated in the study design and coordination, and helped to interpret the data. EHA drafted the manuscript, and YS and WFA were major contributors in writing the manuscript. All authors read and approved the final manuscript.

Funding This work was supported by the NCI [U01-CA179715 (to C. M. Perou and M. A. Troester), P50-CA058223 (SPORE in breast cancer; C. M. Perou, A. F. Olshan, and M. A. Troester)], the Susan G. Komen for the Cure Foundation (A. F. Olshan, M. A. Troester), the American Institute for Cancer Research Marilyn Gentry Fellowship (to E. H. Allott), University Cancer Research Fund, University of North Carolina at Chapel Hill (E. H. Allott, A. F. Olshan, M. A. Troester).

Data availability The datasets used and/or analyzed during the current study are available from the corresponding author on reasonable request.

\section{Compliance with ethical standards}

Conflict of interest C. M. Perou is a consultant, an equity stock holder and Board of Director Member of BioClassifier LLC. C. M. Perou is also listed as an inventor on a patent application on the PAM50 molecular assay. H. S. Earp is a consultant and a stock holder for Meryx. The other authors declare that they have no competing interests. 
Ethical approval The study was approved by the Office of Human Research Ethics at the University of North Carolina at Chapel Hill (UNC).

Informed consent Informed consent was obtained from each participant.

Open Access This article is distributed under the terms of the Creative Commons Attribution 4.0 International License (http://creativeco mmons.org/licenses/by/4.0/), which permits unrestricted use, distribution, and reproduction in any medium, provided you give appropriate credit to the original author(s) and the source, provide a link to the Creative Commons license, and indicate if changes were made.

\section{References}

1. Butler EN, Tse CK, Bell ME, Conway K, Olshan AF, Troester MA (2016) Active smoking and risk of luminal and basal-like breast cancer subtypes in the Carolina breast cancer study. Cancer Causes Control 27(6):775-786. https://doi.org/10.1007/s1055 2-016-0754-1

2. Allott EH, Cohen SM, Geradts J, Sun X, Khoury T, Bshara W, Zirpoli GR, Miller CR, Hwang H, Thorne LB, O'Connor S, Tse CK, Bell MB, Hu Z, Li Y, Kirk EL, Bethea TN, Perou CM, Palmer JR, Ambrosone CB, Olshan AF, Troester MA (2016) Performance of three-biomarker immunohistochemistry for intrinsic breast cancer subtyping in the AMBER consortium. Cancer Epidemiol Biomark Prev 25(3):470-478. https://doi.org/10.1158/1055-9965. EPI-15-0874

3. Sorlie T, Perou CM, Tibshirani R, Aas T, Geisler S, Johnsen H, Hastie T, Eisen MB, van de Rijn M, Jeffrey SS, Thorsen T, Quist $\mathrm{H}$, Matese JC, Brown PO, Botstein D, Lonning PE, BorresenDale AL (2001) Gene expression patterns of breast carcinomas distinguish tumor subclasses with clinical implications. Proc Natl Acad Sci USA 98(19):10869-10874. https://doi.org/10.1073/ pnas. 191367098

4. Anderson WF, Rosenberg PS, Prat A, Perou CM, Sherman ME (2014) How many etiological subtypes of breast cancer: two, three, four, or more? J Natl Cancer Inst. https://doi.org/10.1093/ jnci/dju165

5. Anderson WF, Pfeiffer RM, Dores GM, Sherman ME (2006) Comparison of age distribution patterns for different histopathologic types of breast carcinoma. Cancer Epidemiol Biomark Prev 15(10):1899-1905. https://doi.org/10.1158/1055-9965. EPI-06-0191

6. Matsuno RK, Anderson WF, Yamamoto S, Tsukuma H, Pfeiffer RM, Kobayashi K, Devesa SS, Levine PH (2007) Early- and lateonset breast cancer types among women in the United States and Japan. Cancer Epidemiol Biomark Prev 16(7):1437-1442. https ://doi.org/10.1158/1055-9965.EPI-07-0108

7. Dickens C, Pfeiffer RM, Anderson WF, Duarte R, Kellett P, Schuz J, Kielkowski D, McCormack VA (2016) Investigation of breast cancer sub-populations in black and white women in South Africa. Breast Cancer Res Treat 160(3):531-537. https://doi.org/10.1007/ s10549-016-4019-1

8. Newman B, Moorman PG, Millikan R, Qaqish BF, Geradts J, Aldrich TE, Liu ET (1995) The Carolina breast cancer study: integrating population-based epidemiology and molecular biology. Breast Cancer Res Treat 35(1):51-60

9. Elston CW, Ellis IO (1991) Pathological prognostic factors in breast cancer. I. The value of histological grade in breast cancer: experience from a large study with long-term follow-up. Histopathology 19(5):403-410

10. Ma H, Lu Y, Marchbanks PA, Folger SG, Strom BL, McDonald JA, Simon MS, Weiss LK, Malone KE, Burkman RT, SullivanHalley J, Deapen DM, Press MF, Bernstein L (2013) Quantitative measures of estrogen receptor expression in relation to breast cancer-specific mortality risk among white women and black women. Breast Cancer Res 15(5):R90. https://doi.org/10.1186/bcr3486

11. Parker JS, Mullins M, Cheang MC, Leung S, Voduc D, Vickery T, Davies S, Fauron C, He X, Hu Z, Quackenbush JF, Stijleman IJ, Palazzo J, Marron JS, Nobel AB, Mardis E, Nielsen TO, Ellis MJ, Perou CM, Bernard PS (2009) Supervised risk predictor of breast cancer based on intrinsic subtypes. J Clin Oncol 27(8):1160-1167. https://doi.org/10.1200/JCO.2008.18.1370

12. Troester MA, Sun X, Allott EH, Geradts J, Cohen SM, Tse CK, Kirk EL, Thorne LB, Mathews M, Li Y, Hu Z, Robinson WR, Hoadley KA, Olopade OI, Reeder-Hayes KE, Earp HS, Olshan AF, Carey LA, Perou CM (2018) Racial differences in PAM50 subtypes in the Carolina breast cancer study. J Natl Cancer Inst. https://doi.org/10.1093/jnci/djx135

13. Williams LA, Butler EN, Sun X, Allott EH, Cohen SM, Fuller AM, Hoadley KA, Perou CM, Geradts J, Olshan AF, Troester MA (2018) TP53 protein levels, RNA-based pathway assessment, and race among invasive breast cancer cases. NPJ Breast Cancer 4:13. https://doi.org/10.1038/s41523-018-0067-5

14. Elloumi F, Hu Z, Li Y, Parker JS, Gulley ML, Amos KD, Troester MA (2011) Systematic bias in genomic classification due to contaminating non-neoplastic tissue in breast tumor samples. BMC Med Genom 4:54. https://doi.org/10.1186/1755-8794-4-54

15. Xia Y, Fan C, Hoadley KA, Parker JS, Perou CM (submitted) Genetic determinants of the molecular portraits of epithelial cancers. Nature

16. Curtis C, Shah SP, Chin SF, Turashvili G, Rueda OM, Dunning MJ, Speed D, Lynch AG, Samarajiwa S, Yuan Y, Graf S, Ha G, Haffari G, Bashashati A, Russell R, McKinney S, Group M, Langerod A, Green A, Provenzano E, Wishart G, Pinder S, Watson P, Markowetz F, Murphy L, Ellis I, Purushotham A, BorresenDale AL, Brenton JD, Tavare S, Caldas C, Aparicio S (2012) The genomic and transcriptomic architecture of 2,000 breast tumours reveals novel subgroups. Nature 486(7403):346-352. https://doi. org/10.1038/nature10983

17. Prat A, Carey LA, Adamo B, Vidal M, Tabernero J, Cortes J, Parker JS, Perou CM, Baselga J (2014) Molecular features and survival outcomes of the intrinsic subtypes within HER2-positive breast cancer. J Natl Cancer Inst. https://doi.org/10.1093/jnci/ dju152

18. Brueffer C, Vallon-Christersson J, Grabau D, Ehinger A, Hakkinen J, Hegardt C, Malina J, Chen Y, Bendahl PO, Manjer J, Malmberg M, Larsson C, Loman N, Ryden L, Borg A, Saal LH (2018) Clinical value of RNA sequencing-based classifiers for prediction of the five conventional breast cancer biomarkers: a report from the population-based multicenter sweden cancerome analysis network-breast initiative. JCO Precis Oncol 2:1-18

19. University of North Carolina Microarray Database. https://genom e.unc.edu/pubsup/breastGEO/clinicalData.shtml

20. Harrell JC, Prat A, Parker JS, Fan C, He X, Carey L, Anders C, Ewend M, Perou CM (2012) Genomic analysis identifies unique signatures predictive of brain, lung, and liver relapse. Breast Cancer Res Treat 132(2):523-535. https://doi.org/10.1007/s1054 9-011-1619-7

21. Hatzis C, Pusztai L, Valero V, Booser DJ, Esserman L, Lluch A, Vidaurre T, Holmes F, Souchon E, Wang H, Martin M, Cotrina J, Gomez H, Hubbard R, Chacon JI, Ferrer-Lozano J, Dyer R, Buxton M, Gong Y, Wu Y, Ibrahim N, Andreopoulou E, Ueno NT, Hunt K, Yang W, Nazario A, DeMichele A, O'Shaughnessy J, Hortobagyi GN, Symmans WF (2011) A genomic predictor 
of response and survival following taxane-anthracycline chemotherapy for invasive breast cancer. JAMA 305(18):1873-1881. https://doi.org/10.1001/jama.2011.593

22. Burnham KP, Anderson DR (2002) Model selection and multimodel inference: a practical information-theoretic approach, 2nd edn. Springer, New York

23. Pfeiffer RM, Carroll RJ, Wheeler W, Whitby D, Mbulaiteye S (2008) Combining assays for estimating prevalence of human herpesvirus 8 infection using multivariate mixture models. Biostatistics 9(1):137-151. https://doi.org/10.1093/biostatistics/kxm018

24. Perou CM, Sorlie T, Eisen MB, van de Rijn M, Jeffrey SS, Rees CA, Pollack JR, Ross DT, Johnsen H, Akslen LA, Fluge O, Pergamenschikov A, Williams C, Zhu SX, Lonning PE, BorresenDale AL, Brown PO, Botstein D (2000) Molecular portraits of human breast tumours. Nature 406(6797):747-752. https://doi. org/10.1038/35021093

25. Hoadley KA, Yau C, Wolf DM, Cherniack AD, Tamborero D, Ng S, Leiserson MD, Niu B, McLellan MD, Uzunangelov V, Zhang J, Kandoth C, Akbani R, Shen H, Omberg L, Chu A, Margolin AA, Van't Veer LJ, Lopez-Bigas N, Laird PW, Raphael BJ, Ding L, Robertson AG, Byers LA, Mills GB, Weinstein JN, Van Waes C, Chen Z, Collisson EA, Cancer Genome Atlas Research N, Benz CC, Perou CM, Stuart JM (2014) Multiplatform analysis of 12 cancer types reveals molecular classification within and across tissues of origin. Cell 158(4):929-944. https://doi.org/10.1016/j. cell.2014.06.049

26. Kerlikowske K, Gard CC, Tice JA, Ziv E, Cummings SR, Miglioretti DL, Breast Cancer Surveillance C (2017) Risk factors that increase risk of estrogen receptor-positive and -negative breast cancer. J Natl Cancer Inst. https://doi.org/10.1093/jnci/djw276

27. Palmer JR, Viscidi E, Troester MA, Hong CC, Schedin P, Bethea TN, Bandera EV, Borges V, McKinnon C, Haiman CA, Lunetta K, Kolonel LN, Rosenberg L, Olshan AF, Ambrosone CB (2014) Parity, lactation, and breast cancer subtypes in African American women: results from the AMBER Consortium. J Natl Cancer Inst. https://doi.org/10.1093/jnci/dju237

28. Millikan RC, Newman B, Tse CK, Moorman PG, Conway K, Dressler LG, Smith LV, Labbok MH, Geradts J, Bensen JT, Jackson S, Nyante S, Livasy C, Carey L, Earp HS, Perou CM (2008) Epidemiology of basal-like breast cancer. Breast Cancer Res Treat 109(1):123-139. https://doi.org/10.1007/s10549-007-9632-6

29. Sant M, Gatta G, Micheli A, Verdecchia A, Capocaccia R, Crosignani P, Berrino F (1991) Survival and age at diagnosis of breast cancer in a population-based cancer registry. Eur J Cancer 27(8):981-984

30. Muguti GI (1993) Experience with breast cancer in Zimbabwe. J R Coll Surg Edinb 38(2):75-78

31. Chie WC, Chen CF, Lee WC, Chen CJ, Lin RS (1995) Ageperiod-cohort analysis of breast cancer mortality. Anticancer Res 15(2):511-515

32. Anderson WF, Jatoi I, Devesa SS (2005) Distinct breast cancer incidence and prognostic patterns in the NCI's SEER program: suggesting a possible link between etiology and outcome. Breast Cancer Res Treat 90(2):127-137. https://doi.org/10.1007/s1054 9-004-3777-3

33. Jacquemier J, Padovani L, Rabayrol L, Lakhani SR, PenaultLlorca F, Denoux Y, Fiche M, Figueiro P, Maisongrosse V, Ledoussal V, Martinez Penuela J, Udvarhely N, El Makdissi G, Ginestier C, Geneix J, Charafe-Jauffret E, Xerri L, Eisinger F, Birnbaum D, Sobol H, European Working Group for Breast Screening P, Breast Cancer Linkage C (2005) Typical medullary breast carcinomas have a basal/myoepithelial phenotype. J Pathol 207(3):260-268. https://doi.org/10.1002/path.1845

34. Stoppa-Lyonnet D, Ansquer Y, Dreyfus H, Gautier C, GauthierVillars M, Bourstyn E, Clough KB, Magdelenat H, Pouillart P, Vincent-Salomon A, Fourquet A, Asselain B (2000) Familial invasive breast cancers: worse outcome related to BRCA1 mutations. J Clin Oncol 18(24):4053-4059. https://doi.org/10.1200/ JCO.2000.18.24.4053

35. Collins LC, Botero ML, Schnitt SJ (2005) Bimodal frequency distribution of estrogen receptor immunohistochemical staining results in breast cancer: an analysis of 825 cases. Am J Clin Pathol 123(1):16-20

36. Harvey JM, Clark GM, Osborne CK, Allred DC (1999) Estrogen receptor status by immunohistochemistry is superior to the ligand-binding assay for predicting response to adjuvant endocrine therapy in breast cancer. J Clin Oncol 17(5):1474-1481

37. Rimm DL, Giltnane JM, Moeder C, Harigopal M, Chung GG, Camp RL, Burtness B (2007) Bimodal population or pathologist artifact? J Clin Oncol 25(17):2487-2488. https://doi.org/10.1200/ JCO.2006.07.7537

38. Butler EN, Bensen JT, Chen M, Conway K, Richardson DB, Sun X, Geradts J, Olshan AF, Troester MA (2018) Prediagnostic smoking is associated with binary and quantitative measures of ER protein and ESR1 mRNA expression in breast tumors. Cancer Epidemiol Biomark Prev 27(1):67-74. https://doi. org/10.1158/1055-9965.EPI-17-0404

39. Muftah AA, Aleskandarany M, Sonbul SN, Nolan CC, Diez Rodriguez M, Caldas C, Ellis IO, Green AR, Rakha EA (2017) Further evidence to support bimodality of oestrogen receptor expression in breast cancer. Histopathology 70(3):456-465. https://doi. org/10.1111/his.13089

40. Wang J, Wen S, Symmans WF, Pusztai L, Coombes KR (2009) The bimodality index: a criterion for discovering and ranking bimodal signatures from cancer gene expression profiling data. Cancer Inform 7:199-216

Publisher's Note Springer Nature remains neutral with regard to jurisdictional claims in published maps and institutional affiliations.

\section{Affiliations}

\section{Emma H. Allott ${ }^{1,9}$ (1) - Yue Shan ${ }^{2}$ - Mengjie Chen ${ }^{3}$. Xuezheng Sun ${ }^{4}$. Susana Garcia-Recio ${ }^{5}$. Erin L. Kirk ${ }^{4}$. Andrew F. Olshan ${ }^{4,5} \cdot$ Joseph Geradts $^{6} \cdot$ H. Shelton Earp ${ }^{5,7} \cdot$ Lisa A. Carey ${ }^{5,7} \cdot$ Charles M. Perou $^{5} \cdot$ Ruth M. Pfeiffer ${ }^{8}$. William F. Anderson ${ }^{8}$. Melissa A. Troester ${ }^{4,5,10}$}

Yue Shan

yshan@live.unc.edu

Mengjie Chen

mengjiechen@uchicago.edu
Xuezheng Sun

amysun@email.unc.edu

Susana Garcia-Recio

sugarcia@email.unc.edu 
Erin L. Kirk

ekirk@email.unc.edu

Andrew F. Olshan

andy_olshan@unc.edu

Joseph Geradts

joseph.geradts@duke.edu

H. Shelton Earp

shelton_earp@med.unc.edu

Lisa A. Carey

lisa_carey@med.unc.edu

Charles M. Perou

chuck_perou@med.unc.edu

Ruth M. Pfeiffer

pfeiffer@mail.nih.gov

William F. Anderson

wanderso1@me.com

1 Centre for Cancer Research and Cell Biology, Queen's University Belfast, Belfast, UK

2 Department of Biostatistics, University of North Carolina at Chapel Hill, Chapel Hill, NC, USA
3 Departments of Medicine and Human Genetics, University of Chicago, Chicago, IL, USA

4 Department of Epidemiology, University of North Carolina at Chapel Hill, Chapel Hill, NC, USA

5 Lineberger Comprehensive Cancer Center, University of North Carolina at Chapel Hill, Chapel Hill, NC, USA

6 Department of Population Sciences, City of Hope, Duarte, CA, USA

7 Department of Medicine, University of North Carolina at Chapel Hill, Chapel Hill, NC, USA

8 Division of Cancer Epidemiology and Genetics, National Cancer Institute, Bethesda, MD, USA

9 Centre for Cancer Research and Cell Biology, Queen's University Belfast, Health Sciences Building, Room 2.12, 97 Lisburn Road, Belfast BT9 7AE, Northern Ireland, UK

10 Department of Epidemiology, University of North Carolina at Chapel Hill, CB 7435, 135 Dauer Drive, Chapel Hill, NC 27599, USA 